Case

Report

\title{
A Solitary Mixed Squamous Cell and Glandular Papilloma of the Lung
}

\author{
Yoshiki Kozu, MD, PhD,${ }^{1}$ Tomohiro Maniwa, MD, ${ }^{1}$ Yasuhisa Ohde, MD, PhD,${ }^{1}$ \\ and Takashi Nakajima, $\mathrm{MD}, \mathrm{PhD}^{2}$
}

\begin{abstract}
Mixed squamous cell and glandular papilloma (mixed papilloma) of the lung is exceedingly rare, with only 18 cases reported in the literature. Herein, we report a case of mixed papilloma and its associated immunohistochemical and positron emission tomographic (PET) findings. A 60-year-old Japanese male with a smoking history of 40 pack-years presented with a smooth-edged pulmonary lesion in the right 55 segment on computed tomography (CT). F18-fluorodeoxyglucose (FDG) PET revealed abnormally increased FDG uptake in the mass (maximum standardized uptake value, 3.4). We performed right middle lobectomy and combined partial resection of the $S 8$ segment. The $1.8-\mathrm{cm}$ tumor that filled the enlarged lumen of the $\mathrm{B5} b$ was histologically diagnosed as mixed papilloma. Immunohistochemically, the pseudostratified columnar epithelium was positive for cytokeratin (CK) 5/6 and CK7. p40 positivity was predominant in the basal and squamous cells. Thyroid transcription factor-1 and carcinoembryonic antigen were negative on immunostaining. Malignant features were absent. The postoperative course has been uneventful for 3 months after the surgery. No recurrences were reported after the surgical resection of the mixed papilloma. Therefore, surgical resection may be considered the mainstay of curative treatment.
\end{abstract}

Keywords: solitary endobronchial papilloma, mixed squamous cell and glandular papilloma, immunohistochemistry, positron emission tomography

\section{Introduction}

Solitary endobronchial papillomas (SEPs) are extremely rare neoplasms. At bronchoscopy, SEPs are reported to be found in only 3.95 cases in 100000 patients per year. ${ }^{1)}$

${ }^{1}$ Division of Thoracic Surgery, Shizuoka Cancer Center, Nagaizumi, Shizuoka, Japan

${ }^{2}$ Division of Pathology, Shizuoka Cancer Center, Nagaizumi,

Shizuoka, Japan

Received: March 4, 2013; Accepted: May 27, 2013

Corresponding author: Yoshiki Kozu, MD, PhD. Division of Thoracic Surgery, Shizuoka Cancer Center, Shimonagakubo 1007, Nagaizumi, Shizuoka 411-8777, Japan

Email: y.kozu@scchr.jp

(C)2014 The Editorial Committee of Annals of Thoracic and Car-

diovascular Surgery. All rights reserved.
SEPs are subclassified into three categories according to histological type as follows: squamous cell papilloma, glandular papilloma, and mixed squamous cell and glandular papilloma (mixed papilloma). ${ }^{2)}$ Of these types, mixed papilloma is the most uncommon, with only 18 cases reported in the English literature. ${ }^{1-9)}$ Thus, its clinicopathological features remain unclear. Herein, we report a case of mixed papilloma and its associated immunohistochemical and positron emission tomographic (PET) findings.

\section{Case Report}

A 60-year-old Japanese male with a smoking history of 40 pack-years was noted to have an abnormal lesion in the right lung by routine health examination and was 

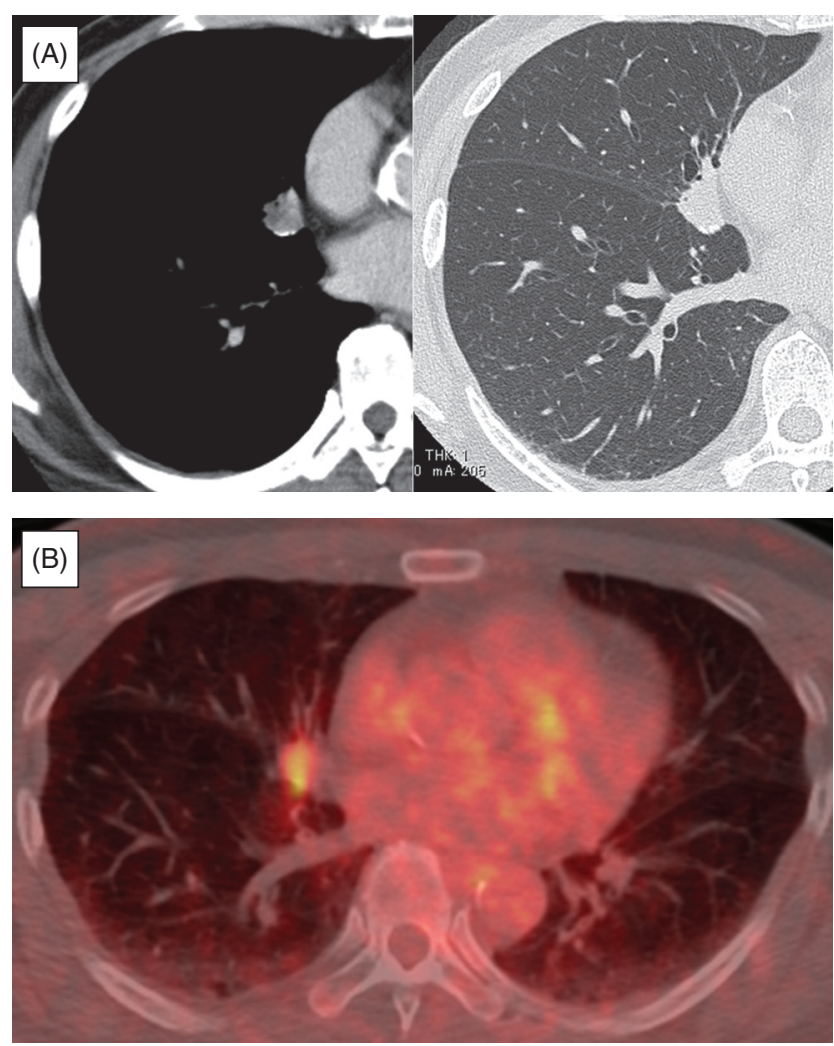

Fig. 1 (A) Axial contrast-enhanced chest computed tomographic (CT) scan revealing a smooth-edged pulmonary lesion in the right S5 segment, near the inferior hilum. (B) F18-fluorodeoxyglucose (FDG) positron emission tomographic (PET) image revealing the abnormally increased FDG uptake (maximum standardized uptake value, 3.4 ) in the nodule. No other abnormally increased FDG uptake was detected.

thus referred to the Shizuoka Cancer Center Hospital, Shizuoka, Japan. He had no history of neoplasm other than acoustic neurinoma. The serum carcinoembryonic antigen (CEA) level was slightly elevated to $5.1 \mathrm{ng} / \mathrm{mL}$, but the other serum tumor markers, including cytokeratin (CK) 19 fragment, neuron specific enolase, and pro-gastrinreleasing peptide, were all within normal limits. An axial contrast-enhanced chest computed tomographic (CT) scan revealed a smooth-edged pulmonary lesion in the right S5 segment, near the inferior hilum (Fig. 1A). With no contrast enhancement, the diameter of the nodule was approximately $1.8 \mathrm{~cm}$. The radiological appearance of the tumor on CT scan was mostly unchanged during the first 3 months after diagnosis. F18-fluorodeoxyglucose (FDG) PET revealed abnormally increased FDG uptake in the mass (maximum standardized uptake value, 3.4), but no other abnormally increased FDG uptake was detected (Fig. 1B). To exclude a malignancy, fiberoptic bronchoscopy and brush cytological examination were performed. The cytological examination result indicated the presence of class IV cells (strongly suggestive of malignancy). We performed right middle lobectomy and combined partial resection of the S8 segment. The result of an intraoperative pathological examination using a frozen section was suggestive of a pulmonary papilloma. Mediastinal lymphadenectomy was therefore omitted. The final pathological diagnosis was a solitary mixed papilloma of the lung. Adjuvant therapy was not provided because of the absence of malignant features. The postoperative course of the patient was uneventful for 3 months after surgery.

\section{Pathological Findings}

A whitish solid nodule measuring $1.8 \times 1.8 \times 1.5 \mathrm{~cm}$ was observed filling the enlarged lumen of the B5b, near the resected end of the middle lobe bronchus (Fig. 2A). Microscopically, the tumor showed prominent papillary growth of the bronchial columnar epithelium in the lumen surrounded by a thick fibrous bronchial wall (Fig. 2B). The pseudostratified columnar epithelium consisted of ciliated and non-ciliated columnar cells and many mucous cells (Fig. 2C). Some papillomatous fronds were covered by squamous epithelium (Fig. 2D). The lung parenchyma surrounding the tumor nodule showed localized collapse and fibrosis, in which prominent alveolar and bronchiolar cell hyperplasia were observed. Tumorlets were also found in this area. Immunohistochemically, the pseudostratified columnar epithelium was positive for CK 5/6 and CK7 but negative for CK20. Immunopositivity for p40 staining was mostly observed in the basal and squamous cells (Fig. 2E). Ki-67 immunostaining demonstrated positive cells in the basal layers of the epithelium. Thyroid transcription factor-1 and CEA were negative on immunostaining. The tumorlets were positive for chromogranin A. On the basis of these morphological and immunohistochemical findings, we diagnosed the patient with mixed papilloma of the lung.

\section{Discussion}

A mixed papilloma, the most uncommon histological subtype of SEP, is composed of squamous and glandular epithelia. Thus far, only 18 cases have been reported in the English literature. ${ }^{1-9)}$ The incidence of mixed papilloma has a male sex predilection (16:3), and most (75\%) 

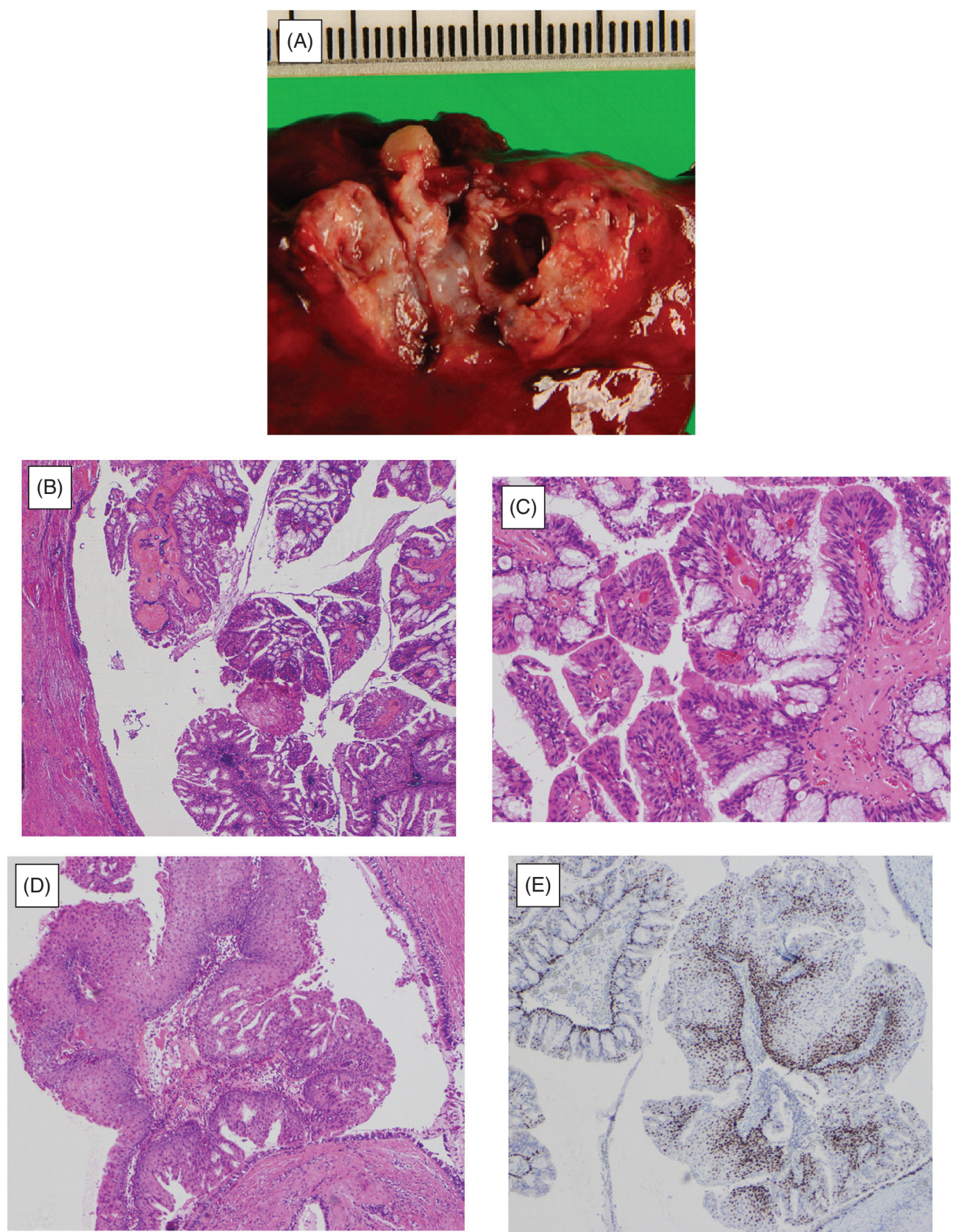

Fig. 2 (A) A whitish solid nodule was observed filling the enlarged lumen of the B5b, near the resected end of the middle lobe bronchus. (B) The tumor showing prominent papillary growth of a bronchial columnar epithelium (hematoxylin-eosin staining). (C) The pseudostratified columnar epithelium consisting of ciliated and non-ciliated columnar cells and many mucous cells (hematoxylin-eosin staining). (D) The squamous epithelium was found (hematoxylin-eosin staining). (E) Immunostaining revealing p40 in the basal and squamous cells.

of the patients had a history of smoking. The age distribution demonstrated peaks in the fifth and sixth decades.

Herein, we referred to the FDG accumulation during PET in the mixed papilloma (maximum standardized uptake value, 3.4). The accumulation made us suspect malignancy preoperatively; however, no evidence of malignancy was observed on pathological examination. Abiko, et al. initially described the PET findings of this disease, showing highly increased FDG accumulation (maximum standardized uptake value, 9.01).3) We suggest considering mixed papilloma as a possible diagnosis in cases with PET results positive for a solitary 
pulmonary nodule.

Squamous cell and mixed papillomas have the potential to develop into a carcinoma. In previous reports, 5 mixed papillomas had malignant features (squamous cell carcinoma in situ in 2 cases, adenocarcinoma in 1, lowgrade differentiation cells of carcinoma in 1, and pleomorphic carcinoma in 1). ${ }^{1,2,6,8)}$ The putative risk factors for malignant transformation are smoking and human papillomavirus (HPV) infection. Given that HPV was detected in squamous cell papilloma but not in mixed papilloma ( 0 of 9 cases), smoking status might play more important role in the malignant transformation of mixed papilloma.

The mainstay of treatment for mixed papilloma is surgical resection, when possible. In case of a limited endobronchial lesion, endoscopic therapy is also an option. ${ }^{7)}$ In the 9 cases of mixed paillomas for which follow-up data were obtained, no recurrences were reported after surgical resection, regardless of whether malignant features were present. As long as complete resection is achieved, adjuvant therapy may not be necessary for patients with mixed papilloma.

\section{Conclusion}

Mixed squamous cell and glandular papilloma of the lung is exceedingly rare. Surgical resection may be considered the mainstay of curative treatment.

\section{Disclosure Statement}

We have no conflict of interest.

\section{References}

1) Tryfon S, Dramba V, Zoglopitis F, et al. Solitary papillomas of the lower airways: epidemiological, clinical, and therapeutic data during a 22-year period and review of the literature. J Thorac Oncol 2012; 7: 643-8.

2) Flieder DB, Koss MN, Nicholson A, et al. Solitary pulmonary papillomas in adults: a clinicopathologic and in situ hybridization study of 14 cases combined with 27 cases in the literature. Am J Surg Pathol 1998; 22: 1328-42.

3) Abiko T, Koizumi S, Takanami I, et al. 18F-FDGPET/CT findings in primary pulmonary mixed squamous cell and glandular papilloma. Ann Nucl Med 2011; 25: 227-9.

4) Inamura K, Kumasaka T, Furuta R, et al. Mixed squamous cell and glandular papilloma of the lung: a case study and literature review. Pathol Int 2011; 61: 252-8.

5) Kadota K, Haba R, Katsuki N, et al. Cytological findings of mixed squamous cell and glandular papilloma in the lung. Diagn Cytopathol 2010; 38: 913-7.

6) Lagana SM, Hanna RF, Borczuk AC. Pleomorphic (spindle and squamous cell) carcinoma arising in a peripheral mixed squamous and glandular papilloma in a 70-year-old man. Arch Pathol Lab Med 2011; 135: 1353-6.

7) Paganin F, Prevot M, Noel JB, et al. A solitary bronchial papilloma with unusual endoscopic presentation: case study and literature review. BMC Pulm Med 2009; 9: 40.

8) Spencer H, Dail DH, Arneaud J. Non-invasive bronchial epithelial papillary tumors. Cancer $1980 ; \mathbf{4 5}$ : 1486-97.

9) Sung CO, Kim J, Han J. Solitary pulmonary mixed squamous cell and glandular papilloma -a brief case report -. Korean J Pathol 2008; 393: 393-5. 